\title{
Synthesis of mesoporous silica-tethered phosphonic acid sorbents for uranium species from aqueous solutions
}

\author{
Oksana A. Dudarko ${ }^{1,2}$, Chamila Gunathilake ${ }^{2}$, Nilantha P. Wickramaratne ${ }^{2}$, Valeriia \\ V. Sliesarenko ${ }^{1}$, Yuriy L. Zub ${ }^{1}$, Joanna Górka ${ }^{3}$, Sheng Dai ${ }^{3}$, Mietek Jaroniec ${ }^{2 *}$ \\ ${ }^{1}$ Chuiko Institute of Surface Chemistry NAS of Ukraine, 17, General Naumov str., \\ Kyiv 03164 Ukraine \\ ${ }^{2}$ Department of Chemistry and Biochemistry, Kent State University, Kent, OH 44242, \\ USA \\ ${ }^{3}$ Chemical Sciences Division, Oak Ridge National Laboratory, Oak Ridge, \\ TN 37831, USA.
}

\begin{abstract}
One-pot synthesis of highly ordered SBA-15 type silica-tethered phosphonic acid at weakly acidic $\mathrm{pH}$ (3.75) allows for higher loading of phosphonic functionality (up to $33 \%$ ) without significant deterioration of the mesostructure. In this synthesis sodium metasilicate was used instead of tetraethylorthosilicate. The resulting samples featured high specific surface areas $\left(362-533 \mathrm{~m}^{2} / \mathrm{g}\right)$ and well developed mesoporosity. The hexagonal structure and high concentration of phosphonic acid groups (1.0-3.0 $\mathrm{mmol} / \mathrm{g}$ ) in the synthesized samples were established by XRD, TEM, EDS and elemental analysis methods. Since inexpensive sodium metasilicate was used as a source of silica, these materials can be of interest for large scale applications. Experimental studies of the synthesized materials showed that they are effective for extraction of trace uranium species under weak basic conditions $(\mathrm{pH} 8.3)$, which are relevant for practical use such as uranium extraction from seawater.
\end{abstract}

Keywords: Mesoporous silica, block copolymer templating, phosphonic acid-modified silica, uranium recovery from seawater

* Corresponding authors: Tel: +1 330672 3790; Fax: +1 330672 3816; E-mail: jaroniec@kent.edu (M. Jaroniec) 


\section{Introduction}

The formation of functionalized ordered mesostructures that provide a quick access of the sorption centers to metal ions is of great importance from practical point of view. However, this process is complicated in the case of sorbents with high loading of complexing groups. Mann and co-authors showed [1,2] that the preservation of the spatial ordering in mesoporous materials is possible when the synthesis gel possesses less than $20 \%$ (molar) of the organosilane used for introducing the desired organic functionality. Moreover, the removal of template by extraction from the ordered mesophase leads occasionally to the structural deterioration; note that in this case alkylammonium surfactants under alkaline conditions were used. It is known that the synthesis under alkaline conditions leads to mesoporous structures with relatively thin pore walls that reduce their mechanical stability. The use of block copolymer templates such as Pluronic P123 instead of alkylammonium surfactants allows for the synthesis of mesoporous structures with relatively thick pore walls, which enhance the hydrothermal and mechanical stability of the resulting mesostructures $[3,4]$. Similarly as alkylammonium surfactants, the block copolymers can form different types of mesostructures depending on the experimental conditions. Specifically, the self-assembly of silica species in the presence of block copolymer P123 under acidic conditions usually leads to the formation of hexagonally ordered mesostructures [3-6]. At low $\mathrm{pH}$, the protonated poly(ethylene oxide) segments of P123 and silica species are attracted through weak electrostatic interactions mediated by the negatively charged chloride ions; the presence of silica species induces the formation of cylindrical aggregates at concentrations below the critical micelle concentration [7].

The use of tetraethoxysilane (TEOS) together with trifunctional silanes (RO) $)_{3} \mathrm{SiR}$ ' having a functional group ( $\left.\mathrm{R}^{\prime}\right)$ in the initial reaction medium permits one-step attachment of $\mathrm{R}^{\prime}$ groups on the surface of pore walls. However, the incorporation of a high concentration of these functional groups leads to the formation of a bimodal structure, and ultimately also to irregular (amorphous) structure [8,9]. In this case mesopores with small diameters are formed (for example, pore width $=3.5 \mathrm{~nm}$ [8]), which is not typical for block copolymer-templated materials such as SBA-15. Moreover, the concentration of functional groups in these samples was in the range of $0.5 \mathrm{mmol} / \mathrm{g}$ (ordered mesostructure) - $1.00 \mathrm{mmol} / \mathrm{g}$ (disordered mesostructure) [9]. It should be noted that the one-pot synthesis was carried out in strong acidic media so not all complexing groups like amines could be incorporated under such conditions. In addition, alkoxysilanes are expensive reagents. So there is a question: is it possible to replace the aforementioned expensive precursors with cheaper ones such as sodium silicate. The price of the final sorbent is an important factor for its large-scale 
applications. Note that the replacement of hydrochloric acid with other catalysts or adjustment of the reaction medium $\mathrm{pH}$ in the range of 3-5 could cause the formation of materials with disordered porosity [10-13]. According Brinker [14] and Hook [15] the rate of hydrolysis of TEOS at $\mathrm{pH}$ below 4 is higher than the rate of its polymerization. Thus, an increase in $\mathrm{pH}$ speeds up the polymerization and slows down TEOS hydrolysis. So, the hydrolyzed silicate species gather around the micelles, which lead to the formation of wormlike structures. Thus, nanofoam-type materials are formed at $\mathrm{pH}=5$ and higher [10]. Earlier Imai et al. also showed that the change in $\mathrm{pH}$ can cause the transformation of these structures [16].

It is known that phosphonic acid groups form stable complexes with lanthanides and actinides. Therefore, materials with phosphonic acid functionality are widely used for extraction and separation of lanthanides and actinides. [17-27]. There are many reports on the sorption of uranium species from aqueous phases by phosphorus-containing sorbents. After analysis these reports one can note that a wide range complexing groups on the surfaces of different nature has been used. This is especially true for phosphonic or phosphoric acids functionalites; for instance, organosilicas functionalized with phosphorus-containing alkoxysilanes [19,21,25,26], polystyrene resin with ethylenediamine-tris(metylenphosphonic) acid [23], chitosan - tripolyphosphate [24], silica functionalized with orthophosphoric acid [27] and so on. However, there is difficult to find material, which would be effective and prepared in a simple way using inexpensive precursors.

In this work we report the block copolymer-templated synthesis of mesoporous organosilica from inexpensive sodium metasilicate under weak acid conditions (acetic acid). Diethylphosphatoethyltriethoxysilane (DPTS) was chosen for incorporation of P-containing functional groups, because its hydrolysis in acidic medium causes the formation of Pcontaining oligomers $\left[\equiv \mathrm{Si}\left(\mathrm{CH}_{2}\right)_{2} \mathrm{P}(\mathrm{O})(\mathrm{OH})_{2}\right]_{\mathrm{n}}$ [28]. The amount of DPTS in the synthesis gel was varied to study its effect on the porosity and mesostructural ordering. These materials were examined as potential sorbents for recovery of uranium from seawater.

\section{Experimental}

\subsection{Chemicals}

Sodium metasilicate, $\mathrm{Na}_{2} \mathrm{SiO}_{3} \cdot 9 \mathrm{H}_{2} \mathrm{O}$ (Sigma, USA); diethylphosphatoethyltriethoxysilane, $\left(\mathrm{C}_{2} \mathrm{H}_{5} \mathrm{O}\right)_{3} \mathrm{Si}\left(\mathrm{CH}_{2}\right)_{2} \mathrm{P}(\mathrm{O})\left(\mathrm{OC}_{2} \mathrm{H}_{5}\right)_{2}$ (DPTS, 95\%, Gelest, USA); poly(ethylene oxide)poly(propylene oxide)-poly(ethylene oxide) Pluronic $\mathrm{P} 123$ block copolymer, $\left(\mathrm{EO}_{20} \mathrm{RO}_{70} \mathrm{EO}_{20}, 99 \%\right.$, BASF, USA); concentrated acetic acid, $\mathrm{CH}_{3} \mathrm{COOH}$ (99.7\%, Aldrich, USA); ethanol (absolute); uranyl nitrate $\left(\mathrm{UO}_{2}\left(\mathrm{NO}_{3}\right)_{2} 6 \mathrm{H}_{2} \mathrm{O}\right.$, Aldrich, USA); sodium 
chloride ( $\mathrm{NaCl}$, Aldrich, USA); and sodium bicarbonate $\left(\mathrm{NaHCO}_{3}\right.$ Aldrich, USA) were used as received in the synthesis and testing of P-containing mesoporous silica materials.

\subsection{Preparation of P-containing mesoporous silica samples}

Sample 1 was obtained by using the $\mathrm{Na}_{2} \mathrm{SiO}_{3} \cdot 9 \mathrm{H}_{2} \mathrm{O} /$ DPTS molar ratio $=10: 1.0 .25 \mathrm{~cm}^{3}$ of DPTS was pre-hydrolyzed in $7.36 \mathrm{~cm}^{3}$ of concentrated acetic acid at $80^{\circ} \mathrm{C}$ for 6 hours using reflux condenser and oil bath; next the mixture was cooled down to room temperature. The solution of template $\left(0.8 \mathrm{~g}\right.$ of Pluronic P123 block copolymer in $13 \mathrm{~cm}^{3}$ of water) was added to the solution of DPTS. Separately, $2.276 \mathrm{~g}(0.008 \mathrm{M})$ of sodium silicate was dissolved in $10 \mathrm{~cm}^{3}$ of water, and added to the reaction mixture. Next, the resulting suspension was left on oil bath for $1 \mathrm{~h}$ at $40^{\circ} \mathrm{C}$. Finally, the mixture was paced in microwave for $2 \mathrm{~h}$ at $40^{\circ} \mathrm{C}$ with magnetic stirring on and switched to $10 \mathrm{~h}$ at $100^{\circ} \mathrm{C}$ without stirring. The resulting precipitate was filtered and air-dried for a day. Polymeric template was removed by boiling twice the sample in acidified ethanol $\left(30 \mathrm{~cm}^{3}\right.$ per $1 \mathrm{~g}$ of mesophase) under stirring for 12 hours. The final sample was filtered, dried under vacuum at $50^{\circ} \mathrm{C}$ for 3 days.

Note that the above recipe is analogous to that reported in [29]; the difference is in the acidic conditions used. The samples synthesized in this work were prepared at lower $\mathrm{pH}$ (acetic acid) instead of $\mathrm{HCl}$, which was used in [29].

Analogous samples were obtained by the same procedure using the following $\mathrm{Na}_{2} \mathrm{SiO}_{3} \cdot 9 \mathrm{H}_{2} \mathrm{O} / \mathrm{DPTS}$ molar ratios: 10:2 (sample 2), 10:3 (sample 3), and 10:4 (sample 4).

\subsection{Measurements}

The small angle XRD patterns were recorded over a range of $0.50<2 \theta /^{\circ}<2.5$ on a PANanalytical. Inc. X'Pert Pro (MPD) MultiPurpose Diffractometer with $\mathrm{Cu}_{\mathrm{K} \alpha}$ radiation $(0.1540 \mathrm{~nm})$ using an operating voltage of $40 \mathrm{kV}$ and $40 \mathrm{~mA}$, 20s step time and 0.01 step size. Microscope glass slides were used as sample supports. All materials were manually ground prior to the XRD analysis and the measurements were performed at room temperature.

For morphology investigation and elemental composition determination, a FEI Tecnai G2 F20 transmission electron microscope (TEM) supplied with an EDS detector was used. Samples for TEM analysis were dispersed in ethanol by ultrasonication at a moderate concentration ( 5 wt. \%). A Lacy carbon coated, 200-mesh, copper TEM grid was dipped into the sample suspension and then dried under vacuum at $60^{\circ} \mathrm{C}$ for $3 \mathrm{~h}$ prior to analysis. The EDS spectra were collected at 30\% of detector dead-time and 3 min acquisition times. 
SEM photomicrographs taken by scanning electron microscope JSM-6060 LV (JEOL, Japan).

Elemental analysis of the samples for $\mathrm{C}, \mathrm{P}, \mathrm{H}$ was performed in the certified IOC Laboratory of National Academy of Science (Ukraine). The accuracy was $\pm 0.2 \%$. Thermogravimetric (TG) analysis was performed on a TA Instruments TGA 2950 analyzer with $10^{\circ} \mathrm{C} \min ^{-1}$ heating rate.

IR reflectance spectra in the region $4000-400 \mathrm{~cm}^{-1}$ were recorded under ambient conditions on a spectrometer Thermo Nicolet Nexus FTIR with diffuse reflection using the prefix "SMART Collector" with a resolution of $8 \mathrm{~cm}^{-1}$. Samples were mixed with $\mathrm{KBr}$ (Aldrich) in a ratio of 1:20. Prior IR measurements the samples were dried under vacuum.

Textural properties of the synthesized samples were evaluated from the nitrogen adsorption-desorption isotherms obtained with ASAP 2010 volumetric analyzers manufactured by Micrometrics, Inc. (Norcross, GA). Adsorption isotherms were measured at $-196^{\circ} \mathrm{C}$ in the interval of relative pressures from $10^{-6}$ to 0.995 using ultra high purity nitrogen from Praxair Distribution Company (Danbury, CT, USA). Before analysis, samples were degassed under vacuum in the port of the adsorption instrument for $2 \mathrm{~h}$ at $110^{\circ} \mathrm{C}$ until the residual pressure dropped to 6 or less $\mu \mathrm{mHg}$. The Brunauer-Emmett-Teller (BET) [30] surface area was evaluated using adsorption data in the range of $0.05-0.2 \mathrm{p} / \mathrm{p}_{\mathrm{o}}$, whereas the single-point total pore volume was estimated at $0.98 \mathrm{p} / \mathrm{p}_{\mathrm{o}}$ [31]. Pore-size distributions together with the maximum pore diameters $\left(d_{m}\right)$ were determined by Kruk-Jaroniec-Sayari (KJS) method [32] based on the Barrett-Joyner-Halenda (BJH) algorithm [33].

\subsection{Uranium sorption experiments}

Uranium sorption experiments were conducted analogously as in [34] using simulated seawater prepared by dissolving $17 \mathrm{mg}$ of uranyl nitrate $\left(\left[\mathrm{UO}_{2}\left(\mathrm{NO}_{3}\right)_{2} \cdot 6 \mathrm{H}_{2} \mathrm{O}\right]\right), 25.6 \mathrm{~g}$ of sodium chloride $(\mathrm{NaCl})$ and $193 \mathrm{mg}$ of sodium bicarbonate $\left(\mathrm{NaHCO}_{3}\right)$ in $1 \mathrm{~L}$ of DI water. Next, $50 \mathrm{mg}$ of the silica-based sorbent was shaken in $50 \mathrm{~mL}$ of the uranium containing solution for $24 \mathrm{hrs}$, followed by filtration. The quantification of the remaining uranium in solution was determined by inductively coupled plasma optical emission spectrometry (ICP-OES) analysis.

\section{Results and discussion}

The geometry of mesopores for block copolymer-templated silica samples is primarily determined by the structure of micelles in solution and synthesis conditions (chemical properties of the template, composition of synthesis gel, aging conditions, etc.) [35-38]. 
Pluronic P123 forms rod-like micelles under acidic conditions [1], the surface of which attracts the products of hydrolysis of TEOS and trifunctional silanes that condense during hydrothermal treatment to form a solid mesostructure. The self-assembly synthesis was carried out under weak acidic conditions (acetic acid; $\mathrm{pH}=3.75$ ); at this $\mathrm{pH}$ a wormlike mesostructure is formed by P123 block copolymer [10, 39].

The small angle XRD patterns of the synthesized powder-like products are shown in Fig. 1. As can be seen from this figure all of them except sample 1, which has the smallest concentration of functional groups, exhibit a single reflection at $0.8-0.852 \theta^{\circ}$, typical for wormlike mesostructures with uniform pores or weakly ordered mesostructures $[1,36,37]$.

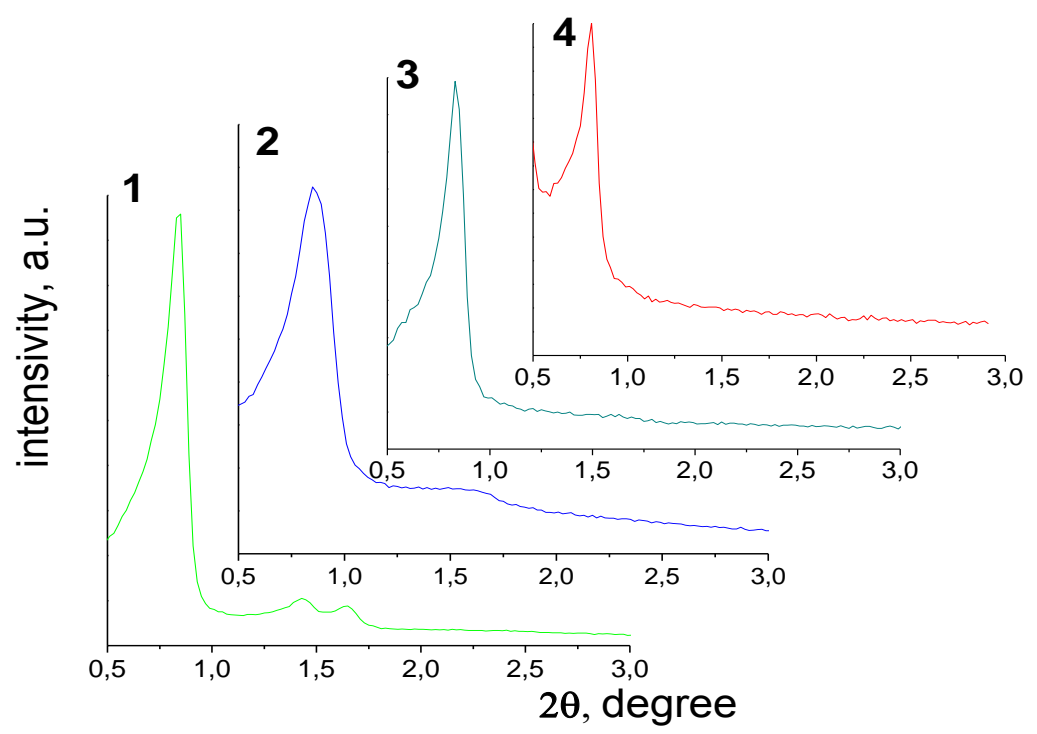

Fig. 1. Powder X-ray diffraction patterns of phosphonic acid-functionalized SBA-15-type mesoporous silicas prepared by using different $\mathrm{Na}_{2} \mathrm{SiO}_{3} \cdot 9 \mathrm{H}_{2} \mathrm{O} / \mathrm{DPTS}$ molar ratios: 10:1 (sample 1), 10:2 (sample 2), 10:3 (sample 3), and 10:4 (sample 4).

The XRD pattern of the extracted sample 1 contains three well-defined reflections at $2 \theta(100)-0.8^{\circ},(110)-1.4^{\circ}$ and $(200)-1.6^{\circ}$, corresponding to the hexagonal structure and indicates well-ordered derived material. This pattern is typical for mesoporous materials SBA-15 type (p6m symmetry group). The spatial ordering of mesoporous silica decreases with increasing DPTS concentration in the reaction solution. Thus, the X-ray diffraction patterns of the samples $\mathbf{2 - 3}$ have no reflections indexed as (110) and (200); the sample 2 features only a low-intensity shoulder in the range of $1.4-1.62 \theta /{ }^{\circ}$. A relative intensity of the main reflection (100) gradually decreases from the sample $\mathbf{1}$ to $\mathbf{2}, \mathbf{3}$, and $\mathbf{4}$ with increasing DPTS amount used in the synthesis (Fig. 1). 
Data obtained by X-ray diffraction analysis have been confirmed by TEM analysis. So, the TEM image of the sample 1 (Fig. 2a) clearly indicates the presence of hexagonal ordering of mesopores. Some elements of hexagonal system are also visible on the image of the sample 2 (Fig. 2b).

The distances between the centers of the pores for the samples $\mathbf{1}$ and $\mathbf{2}$ represent 8.7 and $10.5 \mathrm{~nm}$, respectively. However, the further increase in the concentration DPTS contained in the synthesis gel causes a significant deterioration of the mesostructural ordering. Thus, only some ordered domains can be found on the TEM images of the sample 3 (Fig. 2c), but the TEM images of the sample 4 do not show ordered domains (Fig. 2d).
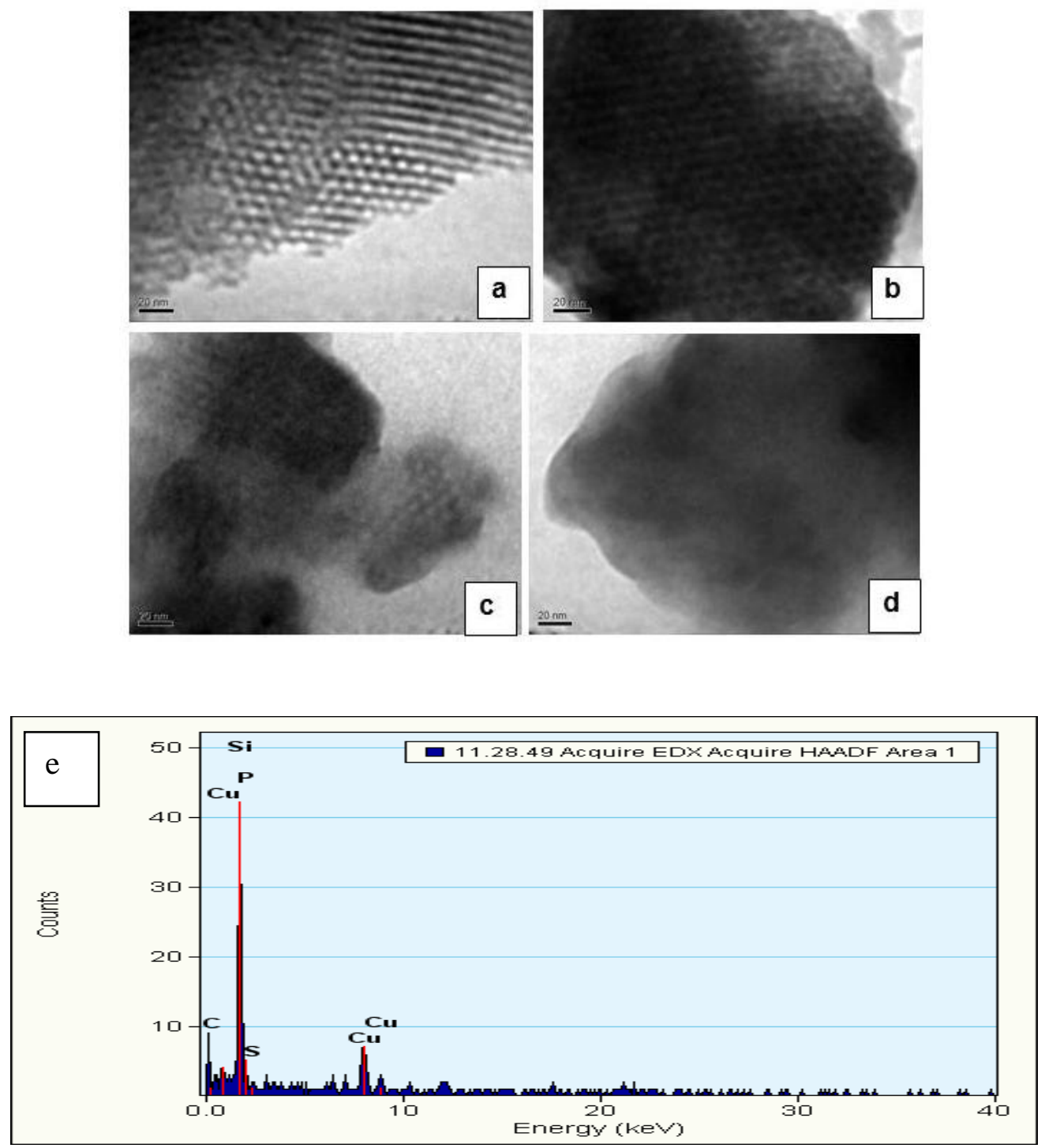

Fig. 2. TEM images of the samples 1 (a), 2 (b), 3 (c) and 4 (d), obtained by TEM and EDS diagram (e) for the sample 2 from one point of its surface. 
Previous reports $[1,2]$ on the synthesis of ordered organosilica mesostructures show that it is extremely difficult to preserve the mesostructural ordering for the synthesis gels containing over $20-25 \%$ of organosilane with a hanging organic group, especially larger one. Note that the content of DPTS in the mixture used for synthesis of the sample $\mathbf{3}$ is about $33 \%$. It is noteworthy that a previous study [10] of the $\mathrm{pH}$ effect on the mesostructure formation in the presence of P123 shows that at pH 3.6 the MSU-3 type mesostructure (sample S12 in [10]) was confirmed by TEM and XRD analysis. It should be mentioned that the samples 1-4 were synthesized at similar $\mathrm{pH}$ but the MSU-3 type structures were not observed.

The EDS analysis of mesoporous functionalized silica (sample 2) reveals the presence of silicon and phosphorus (see Fig. 2e). Since the concentration of functional groups is not very high, then the signal intensity of phosphorus is low. The presence of the phosphoruscontaining functionality in the samples studied was additionally confirmed by elemental analysis (see Table 1).

Table 1. Data of elemental analysis for the synthesized samples.

\begin{tabular}{|c|c|c|c|c|c|c|c|c|}
\hline $\begin{array}{c}\text { Sam } \\
\text { ple }\end{array}$ & $\% \mathrm{C}$ & $\% \mathrm{H}$ & $\% \mathrm{P}$ & $\% \mathrm{Si}$ & $\mathrm{Si} / \mathrm{P}$ & $\begin{array}{c}\mathrm{c}_{\mathrm{m}} \\
\mathrm{mmol} / \mathrm{g}\end{array}$ & $\begin{array}{c}\mathrm{c}_{\mathrm{s}} \\
\mathrm{mmol} / \mathrm{m}^{2}\end{array}$ & $\begin{array}{c}\mathrm{c} \\
\text { group/nm }\end{array}$ \\
\hline $\mathbf{1}$ & 6.9 & 3.0 & 3.0 & 30.3 & $11.2(11.0)$ & $1.0(1.3)$ & 0.0024 & 1.4 \\
\hline $\mathbf{2}$ & 10.5 & 4.4 & 5.5 & 27.2 & $5.5(6.0)$ & $1.9(2.0)$ & 0.0036 & 2.1 \\
\hline $\mathbf{3}$ & 14.6 & 4.4 & 7.5 & 24.8 & $3.7(4.3)$ & $2.6(2.8)$ & 0.0050 & 3.0 \\
\hline $\mathbf{4}$ & 17.0 & 4.9 & 8.4 & 21.0 & $2.6(3.5)$ & $3.0(3.1)$ & 0.0083 & 5.0 \\
\hline
\end{tabular}

Notes: the values listed in the last three columns represent concentrations of phosphonic groups expressed in $\mathrm{mmol} / \mathrm{g}\left(\mathrm{c}_{\mathrm{m}}\right), \mathrm{mmol} / \mathrm{m}^{2}\left(\mathrm{c}_{\mathrm{s}}\right)$ and group $/ \mathrm{nm}^{2}(\mathrm{c})$; these values were calculated by using elemental analysis data for phosphorus (atomic \% $\mathrm{P}$ ); values in parentheses were calculated on the basis of the synthesis gel composition.

The percentage of phosphorus in the samples obtained by elemental analysis was used to calculate the concentration of phosphorus-containing groups (see the values listed in the last three columns of Table 1). The concentration of these groups increases in the following order: from sample 1 to sample $\mathbf{4}$, i.e., with increasing DPTS amount in the synthesis gel. This increase is expected due to the decrease in the value of $\mathrm{Na}_{2} \mathrm{SiO}_{3} / \mathrm{DPTS}$. The values of the ligand concentration calculated on the basis of \% (by elemental analysis) are not significantly different from those obtained on the basis of the synthesis gel composition (see Table 1). 
According to data of elemental analysis the weight loss (the percentage of organic component in the samples 1-4) was calculated. Based on the content of elements in the samples the weight loss data are: $\sim 19.3 \%$ for the sample 1, $21.7 \%$ - sample 2, $30.2 \%$ sample 3, and $37.2 \%$ - sample 4. Clearly the trend of the increasing weight loss in relation to the synthesis gel composition is observed. A little bit larger weight loss as compared to the expected one can be explained by the presence non-hydrolyzed ethoxy groups, and in the case of the sample $\mathbf{1}$ by the presence of carboxyl groups in the structure due to some entrapment of acetic acid in the structure (see IR below).

The SEM images of the synthesized samples are shown in Fig. 3. The morphology of these samples is not typical for typical SBA -15 type materials. The majority of particles are irregular and their size is less than 10 microns. The primary structure consists of irregular disc-type particles of 1-2 $\mu \mathrm{m}$ as in the case of sample $\mathbf{1}$ as shown in Fig. 3a.

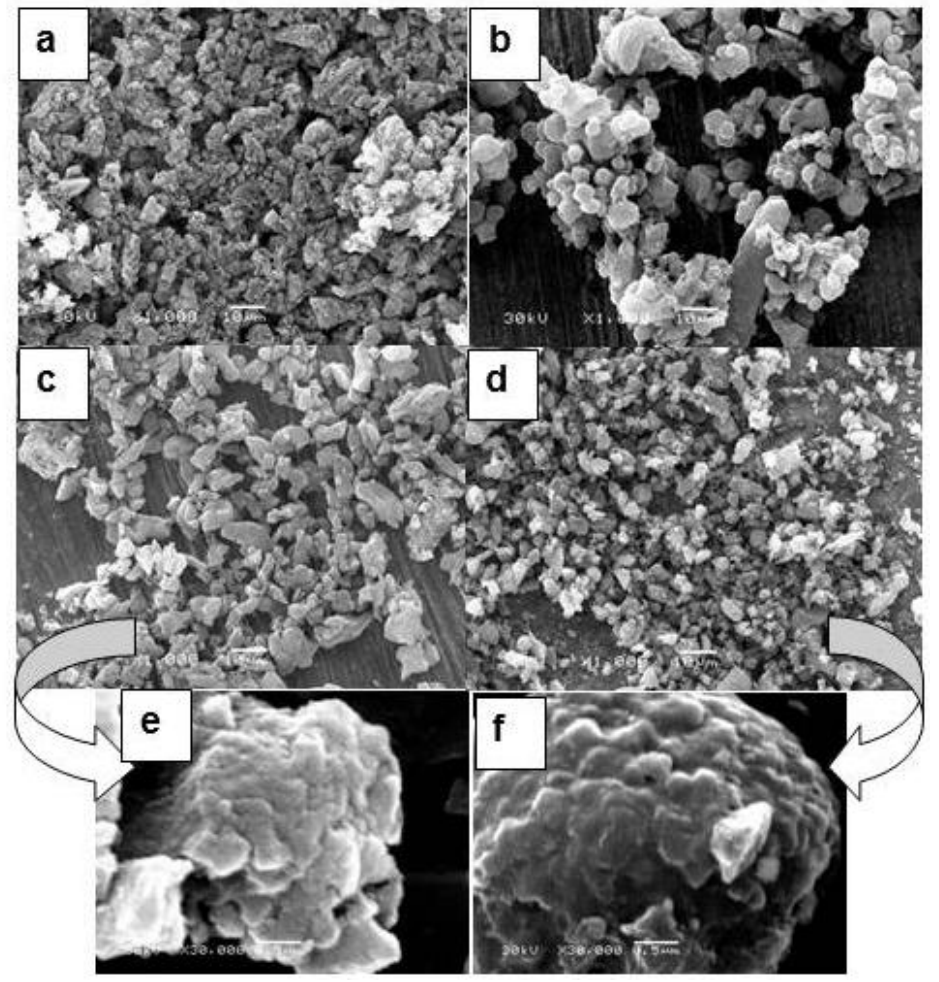

Fig. 3. SEM images of the samples studied 1 (a), 2 (b), 3 (c, e) and 4 (d, f)

These discs are packed into agglomerates and form a secondary structure. In the case of the sample 2 the particles of spherical shape slightly larger (Fig. 3b) are mainly observed. Samples 3 and 4 (Fig. 3c, d) after magnification show agglomerated objects (Fig. 3e, f) composed of smaller primary particles. Thus, an increase in the DPTS amount in the reaction mixture affects significantly the morphology of the synthesized samples. As compared to the morphology of the samples with similar composition, obtained in the presence of hydrochloric acid instead of acetic acid [29], one can argue that the acidity of the medium 
have a significant effect on the morphology of these materials. Therefore, even in the case of microwave-assisted synthesis the agglomeration of primary particles into a solid structure is not prevented.

Chemical identification of the surface layer of the synthesized materials was carried out by IR spectroscopy. Shown in Figure 4 are the IR spectra of the samples studied. The intensive absorption band at $1060-1193 \mathrm{~cm}^{-1}$ can be assigned to $v_{\mathrm{as}}(\mathrm{Si}-\mathrm{O}-\mathrm{Si})$ of polysiloxane skeleton [40,41], which is displayed at high frequencies as a shoulder. Indeed, an intensive shoulder in this band is visible for the samples 1-3, which in the case of the sample 4 (with the highest concentration of functional groups) becomes an individual band at $1207 \mathrm{~cm}^{-1}$ (see Fig. 4).

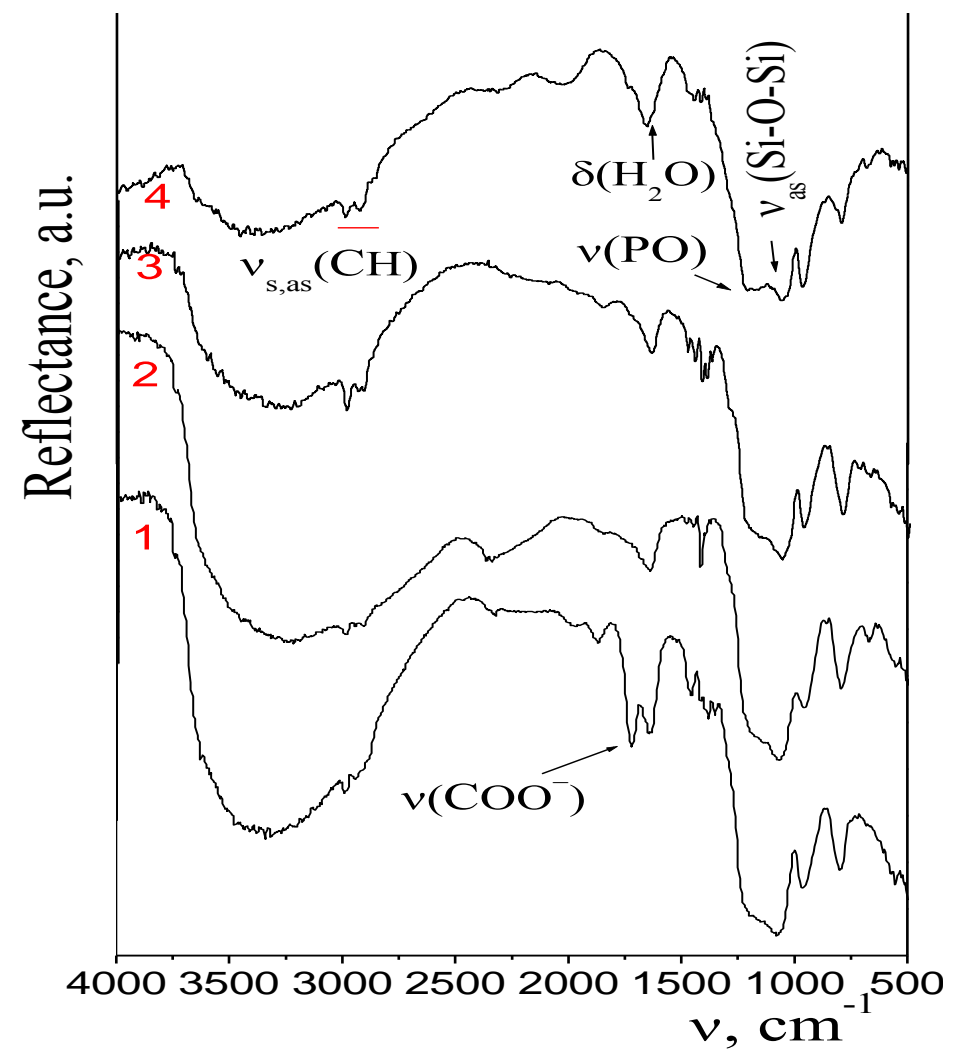

Fig. 4. IR spectra of the samples studied.

This shoulder certainly refers to the absorption band $v(\mathrm{P}=\mathrm{O})$ of the P-containing groups that is present at $1241 \mathrm{~cm}^{-1}$ on the spectrum of initial DPTS. It is shifted to low frequencies by about $35 \mathrm{~cm}^{-1}$ (Fig. 4a-d) indicating the participation of $\mathrm{P}=\mathrm{O}$ groups in hydrogen bonds [40]. This hydrogen bond can be formed by water molecules, as indicated on the IR spectra of all samples at $\sim 1630 \mathrm{~cm}^{-1}$ by absorption band characteristic for the deformation vibrations of $\mathrm{H}_{2} \mathrm{O}$, and above $3000 \mathrm{~cm}^{-1}$ by a broad and intense absorption band due to stretching vibrations of $\mathrm{OH}$ groups of water molecules. However, in the spectrum of the sample $\mathbf{1}$, except for the absorption band at $1641 \mathrm{~cm}^{-1}$, there is an absorption band of medium intensity 
at $1723 \mathrm{~cm}^{-1}$ (Fig. 4). These absorption bands are characteristic of stretching vibrations of $\mathrm{COOH}$ groups [41]. Thus, in the case of the sample 1 the presence of residues of acetic acid, as it was suggested by the data of elemental analysis is confirmed by IR analysis.

The results of elemental analysis of the resulting samples indicate the overestimated values of the carbon content. The IR spectra of these samples suggest that can be primarily caused by the presence of $-\left(\mathrm{CH}_{2}\right)_{2} \mathrm{P}(\mathrm{O})\left(\mathrm{OC}_{2} \mathrm{H}_{5}\right)(\mathrm{OH})$ fragments in these samples. Thus, there is a group of bands of low intensity at the $1360-1480 \mathrm{~cm}^{-1}$ and $2910-2990 \mathrm{~cm}^{-1}$ (Fig. 4). The last can be related to the stretching vibration $v_{\mathrm{s}, \text { as }}(\mathrm{CH})$, while the absorption bands at 1352$1378,1390,1445-1460$ and $1479-1482 \mathrm{~cm}^{-1}$ can be attributed to $\omega\left(\mathrm{CH}_{2}\right), \delta_{\mathrm{s}}\left(\mathrm{CH}_{3}\right), \delta_{\mathrm{as}}\left(\mathrm{CH}_{3}\right)$ and $\delta\left(\mathrm{CH}_{2}\right)$ ethoxygroups. The band of medium intensity, which corresponds to vibrations $\delta\left(\mathrm{Si}-\mathrm{CH}_{2}\right)$ is identified in this region at $1413-1420 \mathrm{~cm}^{-1}[40]$.

Thus, one can conclude that the surface layer containing phosphonic acid residues $\left(\mathrm{CH}_{2}\right)_{2} \mathrm{P}(\mathrm{O})\left(\mathrm{C}_{2} \mathrm{H}_{5} \mathrm{O}\right)_{2}$, which are slightly hydrolyzed; there is a tendency to incorporate acetic acid species into the polysiloxane framework, especially that with low content of functional groups (sample 1) as indicated by IR spectra (Fig. 4) and elemental analysis data.

Analysis of the DTG profiles for the sample $\mathbf{4}$ before and after removal of the polymeric template (Fig. 5, curves 4' and 4, respectively) clearly shows that in the first case an intense peak in the range of $250-350^{\circ} \mathrm{C}$ reflects thermodegradation of $\mathrm{P} 123$ block copolymer. The efficiency of removal of polymeric template from mesostructure with acidified ethanol was confirmed by the absence of this peak in the aforementioned range for the sample after extraction of the template. The same peak is absent in the DTG curves for the others samples (Fig. 5, curves 1-4). It is evident that traces of extracting solvent and physically adsorbed water are removed up to $120^{\circ} \mathrm{C}(2-4 \%)$. 


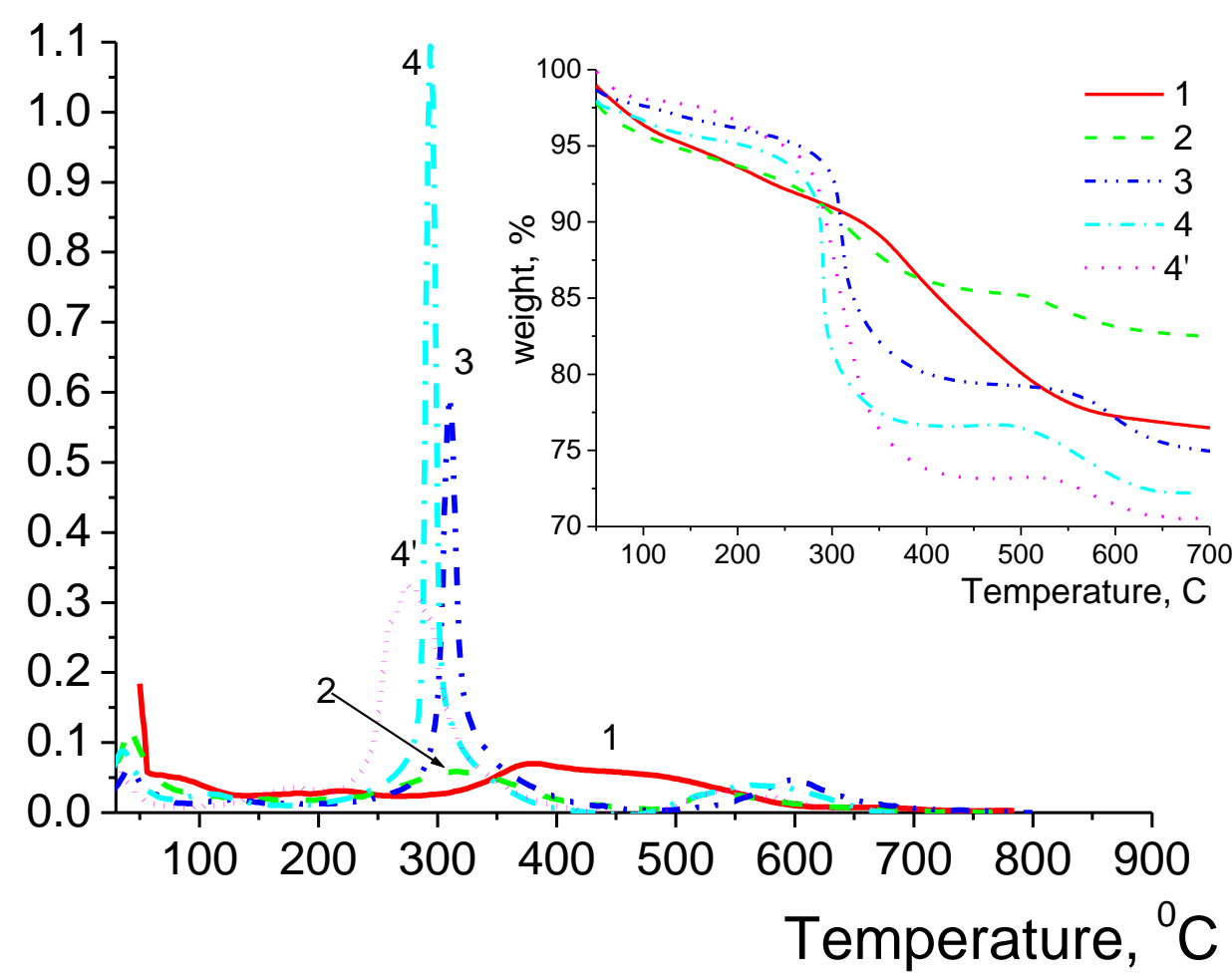

Fig. 5. DTG and TG (inset) curves for the samples 1-4 and 4' after and before the removal of polymeric template, respectively.

The weight loss at higher temperatures is proportional to the concentration of the introduced functional groups, which is reflected by a peak on the DTG curves in the range of temperatures between $275^{\circ} \mathrm{C}$ and $450^{\circ} \mathrm{C}$. The decomposition of organic groups at the aforementioned temperature range is reflected by $11-19 \%$ weight loss for the samples 1-4, and about $22 \%$ weight loss for the sample $4 '$. The DTG curve for the sample 1, the IR spectrum of which indicated the presence of acetic acid is quite interesting (Fig. 5, curve 1). It is obvious that its presence should be reflected by an additional peak in the range $150-250^{\circ} \mathrm{C}$ and the peak at $275-450^{\circ} \mathrm{C}$ is shifted to slightly higher temperature range, $350-$ $500^{\circ} \mathrm{C}$. Note also that the total weight loss for the sample $\mathbf{1}$ is larger than that for the sample 2 . The peak about $3-5 \%$ at the $500-700^{\circ} \mathrm{C}$ can be attributed to the condensation of the neighboring silanol groups to form siloxane bonds.

Low-temperature adsorption-desorption isotherms of nitrogen recorded for all samples are type IV according to the IUPAC classification (Fig. 6a) [31,42]. However, the capillary condensation for the sample $\mathbf{4}$ with the highest content of functional groups is less steep and the hysteresis loop is elongated, which is an indication that pores are nonuniform (broad pore size distribution), and consequently the mesopores are disordered. In 
this case, the pore size distribution (PSD) shows two peaks with maxima corresponding to 3.3 and $6.4 \mathrm{~nm}$, respectively (Fig. 6b). The isotherm recorded for the sample $\mathbf{1}$ is typical for SBA -15 (Fig. 6a) with a steep capillary condensation step, which generates narrow PSD (uniform mesopores) with distinct maximum of about $8.9 \mathrm{~nm}$.

In 2002 Van der Voort and others reported a new type of SBA-15 silica with plugged pores known as PHTS [43,44]. The PHTS materials possess microporous inclusions inside cylindrical mesochannels. Thus, the PSD peak at $\sim 3 \mathrm{~nm}$ on the pore distribution curve (Fig. 6b) for the sample 2, the intensity of which increases with higher concentration of organic groups (samples $\mathbf{3}$ and $\mathbf{4}$ ), can be associated with the formations of plugs in mesopore channels in addition to the complimentary fine pores existing in the SBA-15 mesostructures [45]. The formation of bimodal porous structures is characteristic for the polymer templating synthesis at lower $\mathrm{pH}(3.5-4)$ [10].

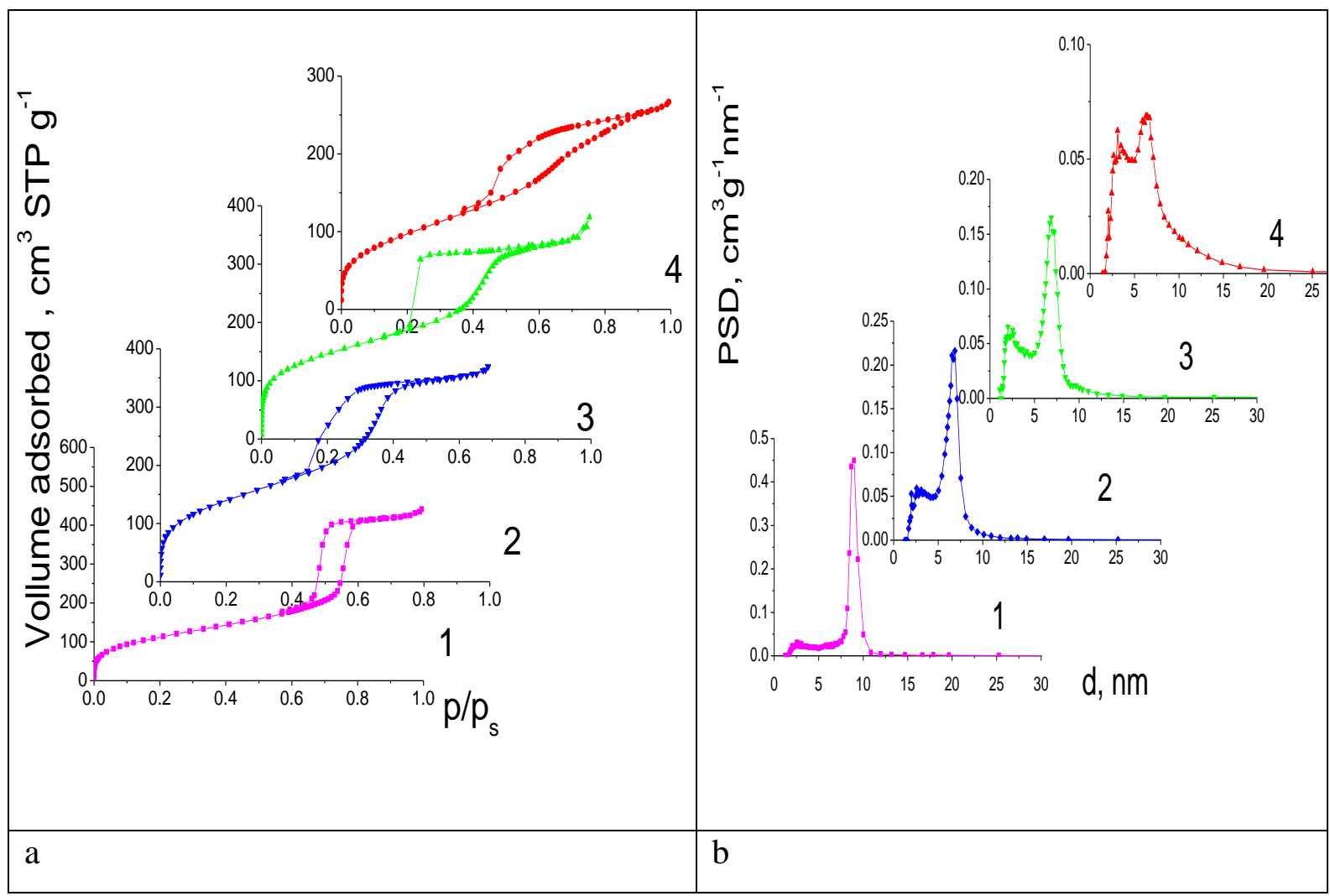

Fig. 6. Nitrogen adsorption-desorption isotherms (panel a) and the corresponding pore size distributions calculated from adsorption branches of the isotherms obtained by KJS method (panel b).

A comparison of the adsorption and structural parameters for the samples studied is shown in Table 2. One can argue that in the case of the samples $\mathbf{2}$ and $\mathbf{3}$ the value of the specific surface area is significant affected by contribution of fine micropores. However, 
there is a general trend for the samples studied; namely, the pore volume and pore diameter decrease with increasing content of functional groups (Table 2).

Table 2. Parameters of the porous structure for the synthesized materials

\begin{tabular}{|l|l|l|l|l|}
\hline Sample & $\begin{array}{l}\text { TEOS/ } \\
\text { DPTS }\end{array}$ & $\mathrm{S}_{\mathrm{BET}}, \mathrm{m}^{2} / \mathrm{g}$ & $\mathrm{V}_{\mathrm{s}}, \mathrm{cm}^{3} / \mathrm{g}$ & $\mathrm{d}_{\mathrm{m}}, \mathrm{nm}$ \\
\hline $\mathbf{1}$ & $10: 1$ & 417 & 0.66 & 8.9 \\
\hline $\mathbf{2}$ & $10: 2$ & 533 & 0.55 & 6.9 \\
\hline $\mathbf{3}$ & $10: 3$ & 515 & 0.56 & 6.9 \\
\hline $\mathbf{4}$ & $10: 4$ & 362 & 0.40 & 6.4 \\
\hline
\end{tabular}

Mesopore diameter $\mathrm{d}_{\mathrm{m}}$ calculated at the maximum of the second peak of the PSD curves; the first peak indicates the presence of complementary fine pores (micropores and small mesopores).

It is known that the cationites with phosphonic acid residues [46,47] form stable complexes with ions of rare earth elements and uranium. Similarly, the mesoporous silicas studied have been decorated with phosphonic acid functionalities that are stable in aqueous solutions. Therefore, it is worthy to test these materials for adsorption of uranium species from aqueous solutions. According to some authors [48] the existence of uranyl ions $\mathrm{UO}_{2}{ }^{2+}$ is possible at $\mathrm{pH} \leq 2.5$. Our previous studies have been focused on adsorption of uranyl ions at $\mathrm{pH}=\sim 2-2.5$ [21,49] At higher $\mathrm{pH}$ values (between 2 and 8) more complex ions such as $\mathrm{UO}_{2}(\mathrm{OH})^{+}, \mathrm{U}_{2} \mathrm{O}_{5}{ }^{2+}$, and $\mathrm{U}_{3} \mathrm{O}_{8}{ }^{2+}$, are present in aqueous solutions [50]. However, a very challenging and practically important task is the extraction of uranium species present in sea water. Under sea water conditions $(\mathrm{pH} \sim 8.3)$ uranium is at oxidation state (VI) mainly in the form of $\left[\mathrm{UO}_{2}\left(\mathrm{CO}_{3}\right)_{3}\right]^{4-}$ and about $10 \%$ of $\mathrm{UO}_{2}(\mathrm{OH})_{3}{ }^{-}$ $[48,51]$. If suitable sorbents are developed, the extraction of the aforementioned uranium species from seawater $(\mathrm{pH} \sim 8.3$ ) could be a feasible alternative to its recovery from ores, which is a laborious process involving acid or base treatments, precipitation and purification steps. According to Sekiguchi and co-workers [52] the state of soluble uranium species in seawater is mainly influenced by $\mathrm{CO}_{2}$ concentration and $\mathrm{pH}$. Therefore, $\mathrm{HCO}_{3}{ }^{-} / \mathrm{CO}_{3}{ }^{2-}$ buffer present in seawater facilitates the formation of uranyl tricarbonate complex $\left[\mathrm{UO}_{2}\left(\mathrm{CO}_{3}\right)_{3}\right]^{4-}$. This complex is stable at $\mathrm{pH} \sim 8.3$ and readily decomposes into two different species such as $\left[\mathrm{UO}_{2}\left(\mathrm{CO}_{3}\right)_{2}\right]^{2-}$ and $\left[\mathrm{UO}_{2}\left(\mathrm{CO}_{3}\right)\right]$ in the $\mathrm{pH}$ ranges of 6-8 and 5-7, respectively [52]. Adsorption of uranium species on the samples studied was 
performed at $\mathrm{pH}$ analogous to that in sea water; the corresponding adsorption capacity data are listed in Table 3.

Table 3. Uranium adsorption data for the samples studied.

\begin{tabular}{|c|c|c|c|c|}
\hline sample & $\begin{array}{c}\text { adsorbent mass } \\
\text { used (mg) }\end{array}$ & $\begin{array}{c}\text { volume of solution } \\
\text { used (mL) }\end{array}$ & $\begin{array}{c}\text { U adsorption capacity } \\
\text { (g-U/kg-ads) }\end{array}$ & $\begin{array}{c}\text { \% of U } \\
\text { adsorbed }\end{array}$ \\
\hline $\mathbf{1}$ & 13.5 & 100 & 24.1 & 40.7 \\
$\mathbf{2}$ & 12.7 & 200 & 54.5 & 43.3 \\
$\mathbf{3}$ & 12.4 & 200 & 11.5 & 8.9 \\
$\mathbf{4}$ & 13.3 & 200 & 10.9 & 9.1 \\
\hline
\end{tabular}

As can be seen from Table 3 the values of uranium adsorption capacity obtained for the samples $\mathbf{1}$ and $\mathbf{2}$ are very high; the adsorption capacity obtained for the sample $\mathbf{2}$ is almost twice larger, which is not surprising because the concentration of phosphonic acid groups in this sample is about twice larger too (Table 1). These organosilica materials possess relatively uniform mesopores with ordered domains, which are easily accessible for relatively large uranium species present in a model aqueous solution that resembles the sea water conditions. The sample $\mathbf{3}$ possesses the surface area similar to that of the sample $\mathbf{2}$, but contains about $30 \%$ more of phosphonic acid groups. In comparison to the sample $\mathbf{3}$, the sample 4 exhibits even more phosphonic acid groups but its surface area is smaller, $352 \mathrm{~m}^{2} / \mathrm{g}$ versus $515 \mathrm{~m}^{2} / \mathrm{g}$ (sample 3 ). Since both samples 3 and $\mathbf{4}$ possess much more phosphonic acid groups than the sample 2, one could expect higher uranium adsorption capacities for the former samples. Table 3 shows that this is not the case. The adsorption capacity for the samples $\mathbf{3}$ and $\mathbf{4}$ is about $11 \mathrm{~g}$ of $\mathrm{U}$ per $\mathrm{kg}$ of the adsorbent; this value is almost four times smaller than that obtained for the sample 2 . As it was mentioned above, the former samples possess plugged mesopores, which is reflected by bimodal shape of PSD, and fine disordered pores (including micropores), which can limit accessibility of some porous domains to the relatively large uranium species. In addition, due to the high concentration of phosphonic acidc groups in the samples $\mathbf{3}$ and $\mathbf{4}$, and the polymeric nature of the surface layer as well as the presence of plugged pores, some organic groups are simply inaccessible to the relatively large uranium species. This inaccessibility can even rise after binding initial uranium species, which block access to other uranium species. This study shows that while a large concentration of phosphonic acid groups is an important factor for adsorption of uranium species under sea water conditions, an equally important factor is the presence of accessible mesoporous network without plugs and pore constrictions, which can exclude some porous domains for uranium species. 


\section{Conclusions}

Synthesis of ordered phosphorus-containing materials of SBA-15 type at weak acidic conditions $(\mathrm{pH} \sim 3.75)$ is improved. The resulting materials featured surface areas of 363 $533 \mathrm{~m}^{2} / \mathrm{g}$, pore volumes of $0.40-0.66 \mathrm{~cm}^{3} / \mathrm{g}$, and mesopore widths of $6.4-8.9 \mathrm{~nm}$. The concentration of phophonic acid groups in these samples varied from 1.0 to $3.0 \mathrm{mmol} / \mathrm{g}$. Since inexpensive sodium metasilicate was used as a source of silica, these materials can be prepared on a large scale for various adsorption applications. For instance, one of the samples exhibited the surface area of $533 \mathrm{~m}^{2} / \mathrm{g}$, pore volume of $0.55 \mathrm{~cm}^{3} / \mathrm{g}$, mesopore width of $6.9 \mathrm{~nm}$, and phosphonic acid concentration of $2.0 \mathrm{mmol} / \mathrm{g}$, which was shown to be optimal for adsorption of uranium species from aqueous solutions $(\mathrm{pH}=8.3$ to mimic sea water conditions); at these conditions about $55 \mathrm{~g}$ of uranium per $\mathrm{kg}$ of the adsorbent was recorded, which illustrates high adsorption capacity of these materials for uranium species.

\section{Acknowledgment}

O.A.D. thanks Fulbright Scholar Program for the financial support of the present work (Grant ID 68120263, 2012-2013). JG and SD thank for support by the U. S. DOE NE Office.

\section{References}

[1] S. L. Burkett, S. D. Sims, S. Mann, Synthesis of hybrid inorganic-organic mesoporous silica by co-condensation of siloxane and organosiloxane precursors. Chem. Commun. 32 (1996) 1367 - 1368.

[2] S. D. Sims, S. L. Burkett, S. Mann, Synthesis of hybrid inorganic-organic mesoporous silica by co-condensation of siloxane and organosiloxane precursors. Mat. Res. Soc. Symp. Proc. 431 (1996) 77 - 82.

[3] D. Zhao, Q. Huo, J. Feng, B. F. Chmelka, G. D. Stucky, Nonionic triblock and star diblock copolymer and oligomeric surfactant syntheses of highly ordered, hydrothermally stable, mesoporous silica structures, J. Am. Chem. Soc. 120 (1998) 6024-6036.

[4] D. Zhao, J. Feng, Q. Huo, N. Melosh, G.H. Fredrickson, B.F. Chmelka, G.D. Stucky, Triblock copolymer syntheses of mesoporous silica with periodic 50 to 300 angstrom pores. Science 279 (1998) 548-552. 
[5] T. Asefa, Z. Tao, Mesoporous silica and organosilica materials - review of their synthesis and organic functionalization. Can. J. Chem. 90 (2012) 1015-1031.

[6] A. Sundblom, C. L. P. Oliveira, A. E. C. Palmqvist, and J. S. Pedersen, Modeling in Situ Small-Angle X-ray Scattering Measurements Following the Formation of Mesostructured Silica J. Phys. Chem. C. 113 (2009) 7706-7713.

[7] M. Imperor-Clerc, P. Davidson, and A. Davidson, Existence of a Microporous Corona around the Mesopores of Silica-Based SBA-15 Materials Templated by Triblock Copolymers. J. Am. Chem. Soc. 122 (2000) 11925-11933.

[8] Y.P. Pan, H. G. Tsai, J. C. Jiang, C. C. Kao, T. L. Sung, P. J. Chiu, D. Saikia, J. H. Chang, H. M. Kao, Probing the nature and local structure of phosphonic acid groups functionalized in mesoporous silica SBA-15. J. Phys. Chem. C 116 (2012) 1658-1669.

[9] Q. Yang, J. Yang, J. Liu, Y. Li, C. Li, Synthesis and characterization of phosphonic acid functionalized organosilicas with bimodal nanostructure. Chem. Mater. 17 (2005) 30193024.

[10] J. Liu, L. Zhang, Q. Yang, C. Li, Structural control of mesoporous silicas with large nanopores in a mild buffer solution. Microporous Mesoporous Mater. 116 (2008) 330338.

[11] S. Y. Chen, S. Cheng, Acid-free synthesis of mesoporous silica using triblock copolymer as template with the aid of salt and alcohol. Chem. Mater. 19 (2007) 30413051.

[12] H. Wang, X. Zhou, M. Yu, Y. Wang, L. Han, J. Zhang, P. Yuan, G. Auchterlonie, J.Zou, C. Yu, Supra-assembly of siliceous vesicles, J. Am. Chem. Soc. 128 (2006) 15992-15993.

[13] H. Wang, Y. Wang, X. Zhou, L. Zhou, J. Tang, J. Lei, C. Yu, Siliceous unilamellar vesicles and foams by using block-copolymer cooperative vesicle templating. Adv. Funct. Mater. 17 (2007) 613-617.

[14] C. J. Brinker, Hydrolysis and condensation of silicates: effects on structure, J. NonCryst. Solids 100 (1988) 31-50.

[15] R. J. Hook, A ${ }^{29} \mathrm{Si}$ NMR study of the sol-gel polymerization rates of substituted ethoxysilanes. J. Non-Cryst. Solids 195 (1996) 1-15.

[16] S. Muto, H. Imai, Relationship between mesostructures and $\mathrm{pH}$ conditions for the formation of silica-cationic surfactant complexes. Micropor. Mesopor. Mater. 95 (2006) 200-205. 
[17] V. S. Brovko, N. K. Skvortsov, V. A. Reyhsveld, Silicaphosphone compounds as ligands and catalysts, in "Chemistry and application practical of silica - and phosphorus containing compounds," (in Russian) Leningrad, 1981, 50-69.

[18] A. Y. Fadeev, A. A. Serdan, G. V. Lisichkin, Chemistry of grafted surface compounds (in Russian), FIZMATLIT, Moscow, 2003.

[19] O. A. Dudarko, G. R. Yurchenko, O. K. Matkovskii, Y. L. Zub, Adsorption properties of polisyloksane xerogels containing remains phosphonic acid in surface layer, Bull. Don. Univ. - Ser. A: Natural Sciences (in Ukrainian) 1 (2007) 221 - 225.

[20] Q. Jia, Z. H. Wang, D. Q. Li, C. J. Niu, Adsorption of heavy rare earth(III) with extraction resin containing bis(2,4,4-trimethylpentyl) monothiophosphinic acid. J. Alloys Compounds 374 (2004) 434-437.

[21] V. V. Milutin, V. M.Gelis, N. A. Nekrasova, I. V. Melnik, O. A. Dudarko, V. V. Sliesarenko, Y. L. Zub, Sorption of Actinide Ions onto Mesoporous PhosphorusContaining Silicas . Radiochemistry 56 (2014) 262-266.

[22] A. M. Safiulina, A. G. Matveev, T.K. Dvoryanchykova, O. A. Synehrybova, D. A. Tatarinov, Acetilcontaining phosphine oxides - new extractants for rare earth metals (in Russian). Non-Ferrous Metals 3 (2012) 73-75.

[23] A. Kadous, M. A. Didi and D. Villemin, A new sorbent for uranium extraction: ethylenediaminotris(methylenephosphonic) acid grafted on polystyrene resin. J. Radioanal. Nucl. Chem. 284 (2010) 431-438.

[24] M. K. Sureshkumar, D. Das, M. B. Mallia and P. C. Gupta, Adsorption of uranium from aqueous solution using chitosan-tripolyphosphate (CTPP) beads. J. Hazard. Mater. 184 (2010) 65-72.

[25] L. Y. Yuan, Y. L. Liu, W. Q. Shi, Y. L. Lv, J. H. Lan, Y. L. Zhao, Z. F. Chai, High performance of phosphonate-functionalized mesoporous silica for U(VI) sorption from aqueous solution. Dalton Trans. 40 (2011) 7446-7453.

[26] W. X. Liang, Y. L. Yong, W. F. Fei, L. Z. Jie, L. J. Hui, L. Y. Lan, F. Y. Xiao, Z. Y. Liang, C. Z. Fang, S. W. Qun, Mesoporous silica SBA-15 functionalized with phosphonate and amino groups for uranium uptake. Sci. China Chem. 55 (2012) 17051711.

[27] M. Colilla, F. Balas, M. Manzano, M. Vallet-Regi, Novel method to enlarge the surface area of SBA-15. Chem. Mater. 19 (2007) 3099-3101.

[28] G. H. Barnes, M. P. David, Synthesis and hydrolytic stability of some organosilicon phosphonate esters. J. Org. Chem. 25 (1960) 1191-1194. 
[29] O. A. Dudarko, C. Gunathilake, V. V. Sliesarenko, Y. L. Zub, M. Jaroniec, Microwaveassisted and conventional hydrothermal synthesis of ordered mesoporous silicas with Pcontaining functionalities. Colloids \& Surfaces A 459 (2014) 4-10.

[30] J. S. Brunauer, P. H. Emmet, E. Teller, Adsorption of gases in multimolecular layers. J. Am. Chem. Soc. 60 (1938) 309-319.

[31] F. Rouquerol, J. Rouquerol, K. S. W. Sing, Adsorption by powders and porous solids. Principles, methodology and applications. Academic Press, New York, 1999.

[32] M. Jaroniec, L.A. Solovyov, Improvement of the Kruk-Jaroniec-Sayari method for pore size analysis of ordered silicas with cylindrical mesopores, Langmuir 22 (2006) 6757-6760.

[33] E. P. Barrett, L. G. Joyner, P. P. Halenda, The determination of pore volume and area distributions in porous substances. I. Computations from nitrogen isotherms. J. Am. Chem. Soc. 73 (1951) $373-380$.

[34] J. Górka, R. T. Mayes, L. Baggetto, G. M. Veith, S. Dai, Sonochemical functionalization of mesoporous carbon for uranium extraction from seawater. J. Mater. Chem. A. 1 (2013) 3016-3026.

[35] N. K. Raman, M. T. Anderson, C. J. Brinker, Template - based approaches to the preparation of amorphous, nanoporous silica's. Chem. Mater. 8 (1996) $1682-1701$.

[36] C. T. Kresge, M. E. Leonowicz, W. J. Roth, J. C. Vartuli, J. S. Beck, Ordered mesoporous molecular sieves synthesized by a liquid - crystal template mechanism. Nature 359 (1991) $710-712$.

[37] S. Beck, J. C. Vartuli, W.J. Roth, M. E. Leonowicz, C. T. Kresge, K. D. Schmitt, C. T. W. Chu , D. H. Olson, E. W. Sheppard, A new family of mesoporous molecular sieves prepared with liquid crystal templates. J. Amer. Chem. Soc. 114 (1992) $10834-10843$.

[38] J.R. Matos, M. Kruk, L.P. Mercuri, M. Jaroniec, L. Zhao, T. Kamiyama, O. Terasaki, T.J. Pinnavaia, Y. Liu: Ordered mesoporous silica with large cage-like pores. J. Am. Chem. Soc. 125 (2003) 821-829

[39] V. B. Fenelonov, Introduction to the physical chemistry of the formation of supramolecular structure of adsorbents and catalysts (in Russian). Publishing House of SB RAS, Novosibirsk, $2^{\text {nd }}$ ed., 2004.

[40] L. V. Daimay, N. B. Colthup, W. G. Fateley, J. G. Grasselli, The handbook of infrared and raman characteristic frequencies of organic molecules. Academic Press, London, 1991.

[41] A. Smith, Applied infrared spectroscopy. Wiley, New York, 1982. 
[42] M. Kruk, M. Jaroniec: Gas adsorption characterization of ordered organic-inorganic nanocomposite materials. Chem. Materials 13 (2001) 3169-3183.

[43] P. Van der Voort, P. I. Ravikovitch, K. P. De Jong, A. V. Neimark, A. H. Janssen, M. Benjelloun, E. Van Bavel, P. Cool, B. M. Weckhuysen, E. F. Vansant, Plugged hexagonal templated silica: a unique micro- and mesoporous composite material with internal silica nanocapsules. Chem. Commun. 38 (2002) 1010-1011.

[44] P. Van der Voort, P. I. Ravikovitch, K. P. D. Jong, M. Benjelloun, E. V. Bavel, A. H. Janssen, A. V. Neimark, B. M. Weckhuysen, E. F. Vansant, A new templated ordered structure with combined micro and mesopores and internal silica nanocapsules, J. Phys. Chem. B. 106 (2002) 5873-5877.

[45] R. Ryoo, C.H. Ko, M. Kruk, V. Antochshuk, M. Jaroniec: Block-copolymer-templated ordered mesoporous silica: Array of uniform mesopores or mesopore-micropore network. J. Phys. Chem. B 104 (2000) 11465-11471.

[46] K. M. Saldadze, A.B. Pashkov, V.S.Titov, Ion-exchange macromolecular compounds (in Russian). Goskhimizdat, Moscow, 1960.

[47] K. M. Saldadze, V. D. Kopylova-Valova, Complexing ion exchangers (in Russian). Khimiya, Moscow, 1980.

[48] M. Sutton, P. Warwick, A. Hall, Uranium (VI) interactions with OPC/PFA grout. J. Environ. Monitoring 5 (2003) 922-928.

[49] O. A. Dudarko, V. P. Goncharik, V. Ya. Semenii, and Yu. L. Zub, Sorption of $\mathrm{Hg}^{2+}$, $\mathrm{Nd}^{3+}, \mathrm{Dy}^{3+}$, and $\mathrm{UO}_{2}{ }^{2+}$ ions at polysiloxane xerogels functionalized with phosphonic acid derivatives. Protection Metals \& Phys. Chem. Surf. 44 (2008) 193-197.

[50] Analytical chemistry of Uranium Ed. by A.P.Vinogradov (in Russian) Ed. of Academy of Science of USSR, Moscow, 1962.

[51] R. Djogic, L. Sipos, M. Branica, Characterization of uranium (VI) in seawater. Limnol. Oceanogr., 31(5),1981122-1131

[52] K.Sekiguchi, K.Saito, S.Konishi, S.Furusaki, Effect of seawater temperature on uranium recovery from seawater using amidoxime adsorbents. Ind. Eng. Chem. Res. 33 (3) (1994) 662-666. 